\title{
Health promotion as school development
}

\author{
Lena A Nilsson \\ Department of Nursing, Health and Culture, University of Trollhattan-Uddevalla, Vanersborg, Sweden
}

\section{Abstract}

Background: Data obtained from international studies of health behaviour among school-age children show evidence of strong relationships between alienation from school and health behaviour such as smoking, alcohol use, physical activity and food choices. This article discusses these connections between health problems and underachievement.

Objective: The aim is to raise the question of whether, and if so, how school development could be a way to handle both the alienation and the health problems.

Design and Results: Interviews and observations were accomplished in association with an evaluation study of "health-promoting school" projects at 15 compulsory schools in central Sweden. Different kinds of encounters between health promotion work and school development were distinguished.

Conclusions: The empirical data indicate possibilities in health promotion projects to develop deliberation and dialogical teaching methods, which include possibilities for dialogue and enhanced learning among underachieving students. These approaches to health promotion could be thought of as salutogenesis or empowerment and are not dissimilar to, and could even be confused with, school development.

Keywords: democracy; empowerment; health behaviour; participation; salutogenesis; school alienation

Received: 18 Feb. 2004; Revised: 15 Mar. 2004; Accepted: 7 Apr. 2004

\section{Introduction}

Some years ago, the headline of an article: Warning, schools can damage your health! (1) aroused this author's curiosity. If this is true, we need more school interventions rather than health interventions. The article refers to World Health Organization (WHO)-initiated studies where the data demonstrate the presence of strong relationships between alienation from school and risk behaviours, including smoking, alcohol use, intake of junk food and lack of physical activity, in more than 10 European countries (1). Traditional school health education strategies are insufficient to tackle this task. A more challenging response is to consider ways of creating more positive experiences of school for young people. Researchers in education confirm these findings in explanations of how definitions of educator roles can contribute to "disabling students" (2) or how "school can create learning problems" (3). Cummins (2) suggests that to promote the empowerment of students, the educator's role must be defined as collaborative, reciprocal and interaction orientated.

\section{Conceptual outlines of school development, health and health promotion}

School is central to the health sector as an institution where children can be reached by measures about the prevention of illness and the promotion of health (4-8). How these measures can best be performed is a question that is open to discussion. The WHO definition of health from 1946 underlines that "health" can be thought about as the absence of illness, but also as physical, mental and social well-being. This well-being dimension means that health can be thought about not only as a medical concept but also as a social scientific and educational concept (9). Following these different dimensions the WHO suggests that the opportunity that schools have to promote health can be divided into parts: first, the school health service and health education; secondly, the school environment and policy ensuing from the health education programmes; and finally education, that is to say, the school itself and its culture, curricula, teaching and learning methods $(6,10)$. This article is about the third of these elements: how schools themselves can 
promote health as an educational science issue about school development. School development forms a diverse field for educational research and practice. In brief, it could be defined as school improvement where students' learning and achievement from different perspectives are central. School development is a complex and even ambiguous notion (11). It could be interpreted in a way that emphasizes the development of democracy, student and teacher participation in problem posing and learning together with local solving of problems. These issues are similar to topics discussed in health promotion work. What health promotion really is, is a far-reaching question. Antonovsky (12-14) confronts what he called "the opposite question": the "salutogenic question". Instead of asking the preventive question: "what caused the problem and how can the problem be prevented?" one can ask, "how can health be reinforced?" Together with empowerment, salutogenesis will be used in the discussion of health promotion and school development later in this article.

\section{Research on health and school achievement}

\section{Poor health inhibits learning}

As stated previously, there are strong relationships between school alienation and health-damaging behaviour. To gain a better understanding of this problem the direction of the relationships should be separated. First, the hypothesis that "poor health inhibits learning" $(15$, p. 111$)$ is examined. To do this requires taking as a point of departure the notion that poor health is the root of the problem and to solve this problem a series of health interventions can be established. When health problems and health behaviour problems are addressed the expectation is that health outcomes will improve. Finally, at the end of a chain of impact, when arguing for health interventions in schools, it is hoped that short-term and long-term educational outcomes will be improved (16).

Health interventions could be arranged and performed in a number of different ways and school achievement may be separated into, for example, education outcomes, education behaviours and student attitudes (17). Relationships between health and school achievement can be regarded as different approaches to the same problem. Focusing on health and initiating health interventions are examples of an approach from a health-educational perspective. In the health research literature this perspective is the dominant perspective adopted when carrying out health-related interventions. This perspective is relevant and accords clearly with school alienation and an inequality perspective: "... healthy children are in a better position to acquire knowledge ... no curriculum is 'brilliant enough to compensate for a hungry stomach or a distracted mind"” (17, p. 220).

\section{Poor learning inhibits health}

The main interest in this article is the other way of looking at what, for both health and educational researchers, could be the same problem. This means adopting an educational perspective that is not dissimilar to that recommended by Hawkins and Catalano (18), who ask whether schools themselves could be sources of risks for health problems, and whether schools and their environments could protect against adolescent health problems.

The ethos of a school, its organization and teaching methods can all contribute to educational outcomes and impact upon the levels of commitment of its students. This statement is a distillation of an extensive body of literature on effective schools and strategies for preventing school failure (see e.g. (10), (19), (20)). These are examples of literature that forms the theoretical foundations for the development of "health-promoting schools", but the extent to which education impacts upon health remains an open question: "Nevertheless, some studies do seem to demonstrate a clear independent effect of education on, for example, levels of risky behaviour and associated morbidity" (21, p. 642).

Whitty et al. (21) claim that the effects of low social class, poor educational achievement, low levels of psychosocial well-being and poor physical and mental health are cumulative. The most obvious way of tackling these inequalities in health is to increase access to material resources: "a serious programme to alleviate child poverty might do far more for boosting attainment ... than any modest intervention in schooling" (21, p. 643).

Nevertheless, schools can make a difference and this statement can function as a platform for the concept of the health-promoting school $(4-6,8)$. The concept of the health-promoting school is a recognition of the fact that schools have an opportunity to contribute to the health of both children and staff in a more comprehensive way 
than has been the case in earlier health education and prevention programmes. According to St Leger (8, pp. 57-58), "The focus on knowledge has shifted from an instructional approach to reflect current understandings about how children learn". The concept has much promise but, as St Leger claims, assessing health gains and school achievement in certain health programmes can be difficult.

\section{Inequality in health}

Emphasizing the hypotheses that poor learning inhibits health could mean stressing inequality perspectives on health (20). In educational science the same problems, i.e. aspects of school failure, form a major area of interest. In this literature, however, health is rarely mentioned and, if at all, often related to studies of either health services or knowledge about health.

Another approach to school achievement is to choose democracy, student participation and dialogue as starting points for health promotion and school development. A perspective of this sort can be of value since it permits a better chance for the inclusion of groups alienated from mainstream schooling. Nutbeam and Aarø (22) emphasize the relationship between health-damaging behaviours and school alienation, and they identify a group of students whom they define as disliking school, reporting below-average school achievement and having no plans for higher education. There is, they claim, no value to be gained from starting more school health programmes as a strategy for reaching this alienated group. Instead, as health researchers, they challenge schools to develop their ethos and classroom practice by encouraging participation from alienated pupils.

\section{Aims and methods}

This study is a response to the health research challenge $(1,22)$ and the aim is to investigate whether some of the activities that ordinarily take place in schools can be performed in a way that promotes achievement in both health and education. A further aim of this article is to discuss whether, and if so how, schools can be developed in a way that promotes a greater awareness of their role in the promotion of health. The interest is concerned with how school can be developed in a direction that emphasizes the promotion of health, especially for those underachieving children who are alienated from mainstream schooling.
The data were collected by visiting 15 compulsory schools, mainly in 1999, in two provinces of central Sweden, in conjunction with a college evaluation (23) of health promotion projects in these schools. Observations and interviews were accomplished with headteachers, teachers, other categories of staff and pupils. The research methodology adopted is inspired by the function of a reflective practitioner (24).

\section{Results and discussion}

The health promotion work that had been offered to the schools ranged from teaching traditional knowledge on health, through methods for dialogue in everyday work, to democratic issues. It appeared to be possible to combine health promotion interventions with school activities. However, intentional combinations where participants adopted both health promotional and educational perspectives concurrently were not discovered. The type of health promotion work that was going on in schools was not dissimilar to, and could even be confused with, activities focused on school development. Many of the activities labelled as "health promotion work" could equally well have been classified as forms of school development. Headteachers commented that the total school situation could be chaotic. The chaos could be understood as dilemmas that could in fact be seen as providing opportunities for cross-fertilization to take place between health promotional and educational activities.

Considering health promotion projects as either something passing through or a rendezvous meant that the project lived its own life in the school (Fig. 1). It would probably not really encounter school activities or be incorporated into school development discussions. It just passed through. Yet the encounter called rendezvous had pronounced qualities. It could mean for example that pupils participated in planning a health campaign week. The pupils decided on the menu, with hamburgers and other popular dishes as a consequence. The atmosphere was comfortable, with a democratic ethos. This example suggests possibilities for the development of deeper participation in both campaign weeks and other activities. It affirms the democratic values, but also the difficulties in achieving a menu with high nutritional value and the risk of participation being only temporary. 


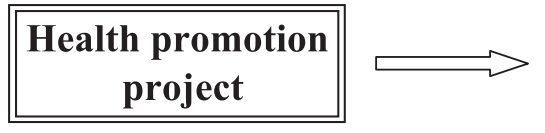

Fig. 1. Health promotion projects taking place alongside schoolwork.

Health promotion projects as forms of deliberation, and even as forms of rivalry, meant that they took their place amongst the school's other activities. How these encounters were shaped depended on how health promotion was presented and how dialogues were conducted within the school (Fig. 2). This figure can be interpreted as an accentuation of health promotion work prior to or superior to school development. Another interpretation of the figure is that health promotion work could also be used as an instrument for school development.

The different forms of encounters are illustrated in Table 1. The encounter called deliberation meant that different methods for participation, such as workshops, value clarifications and problem-based learning, were used as tools for both learning and planning with the staff and pupils. Those methods can be further developed in accordance with the ideas of democracy and knowledge manifested in the Swedish curriculum.

The two forms of encounter, passing through or rendezvous, indicated that the encounter took place beside the ordinary school activities. The encounter became shallow. The other two forms, deliberation or rivalry, gave possibilities for integration in harmony or in conflict between health promotion work and school development (Fig. 3). The dialogue tools used in the health promotion projects were useful for the development of democracy and participation by pupils and staff.
Health promotion and the salutogenic question

"The opposite question" and Antonovsky's reflections on how to construct salutogenic institutions conclude with an invitation to professionals: when you have learned about the salutogenic model try to develop your own field of action in a health promotional manner (14). On the basis of this invitation a range of health promotion enterprises must be identified and distinguished from one another. At one end of this spectrum is a health educational approach teaching people about health to enable them to make healthy choices for their own lifestyles. At the other end of the spectrum, entirely different perspectives on health promotion can be adopted depending on the kind of activity or sector of society that forms the particular point of departure. Antonovsky naturally transfers the responsibility to those whom he sees as the right people: the professionals in each sector.

Knowledge about what health promotion really is remains very much an open question. To construct and develop different sectors in society in a way that encourages health promotion, there will be a need to increase knowledge about the concept of health promotion. What we do have, in the main, are forms of preventive knowledge on which we build health education activities. A salutogenic interpretation of the Swedish curricula is presented in an earlier work (25).

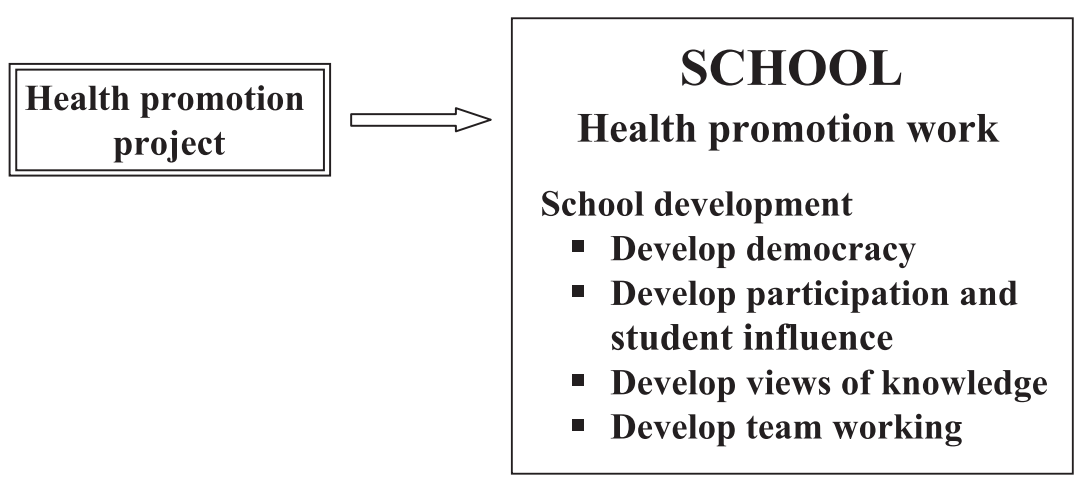

Fig. 2. Health promotion work supporting certain aspects of school development. 


\begin{tabular}{|c|c|c|}
\hline Encounters & Examples from schools & Possibilities \\
\hline Passing through & Health promotion work as project which has a prescribed time span & Attention that health is an important question \\
\hline Rivalry & $\begin{array}{l}\text { Health promotion work as a dilemma: disagreement about time } \\
\text { schedules and teaching }\end{array}$ & Dialogue in working teams could be a way to reach agreement \\
\hline Rendezvous & $\begin{array}{l}\text { Health promotion work as a cosy atmosphere with flowers in the dining-hall, } \\
\text { relaxation and health week campaigns }\end{array}$ & $\begin{array}{l}\text { Student participation in health campaigns can contribute to } \\
\text { improving the school ethos and collaboration }\end{array}$ \\
\hline Deliberation & $\begin{array}{l}\text { Health promotion work as democracy: encouragement to talk and to } \\
\text { listen to each other }\end{array}$ & $\begin{array}{l}\text { Dialogue in different forms where staff and students } \\
\text { participate, express themselves and voice their views }\end{array}$ \\
\hline
\end{tabular}

\section{Health promotion and empowerment}

This study is about the educational sector, to ascertain the extent to which an important concept within the field, i.e. school development, could also have a health promotional effect. The concept of empowerment used in health promotion (26-28) could also be used for comparison with conceptions of learning and success in school (2).

The twin concepts of participation and democracy could be seen as central to the process of school development in Sweden. In health promotion work participation and democracy are equally central, which is underlined in the empowerment model. Therefore, health promotion work could be used as a tool in certain aspects of school development. The term "tool" refers to different, miscellaneous types of training in conducting dialogues between different categories of professionals working in schools, and between pupils and their teachers.

Examples of how such dialogues can be performed and stimulated can be found in many schools, both those that label themselves "health promoting" and those that are highly interested in school development. This means, essentially, that an encounter has been realized. The most important precondition necessary for fruitful encounters to take place is that a wide and non-traditional conception of health is adopted. When focusing on participation and democracy, health promotion work and school development become allied with one another and, even though they have divergent points of departure and quite different perspectives, they address the same issues and the same problems. How these issues can be further advanced is elaborated in the author's thesis (29).

\section{Development in teaching school subjects}

As another example of how health promotion work and school development can be combined, an agricultural project can be used. This project is a part of the education in different school subjects. Farmers are responsible for the cultivation, in which pupils participate. In the project the children learn about why, how and when to sow, and take care of, tend and reap potatoes and vegetables. Different kinds of learning turn out as part of the schedule for most subjects (Fig. 4). Teachers, farmers and school meal staff collaborate in education, production of foodstuffs and cooking the meals. An evaluation of the project shows that the pupils claim that they learn how to manage in life and how to work together, and that they are really needed for the successful production of food.

This agricultural project is not foremost a health promotion or health education project. It

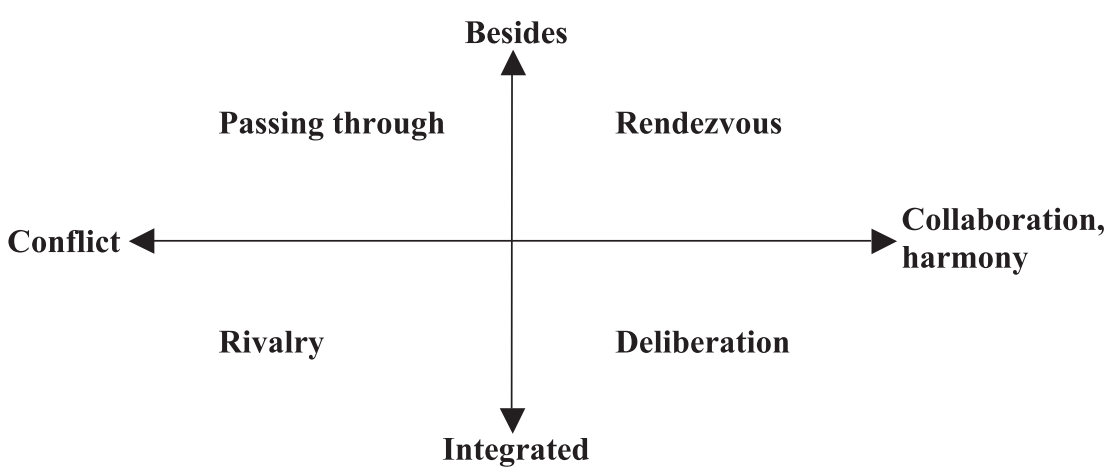

Fig. 3. Encounter between health promotion work and school development. 


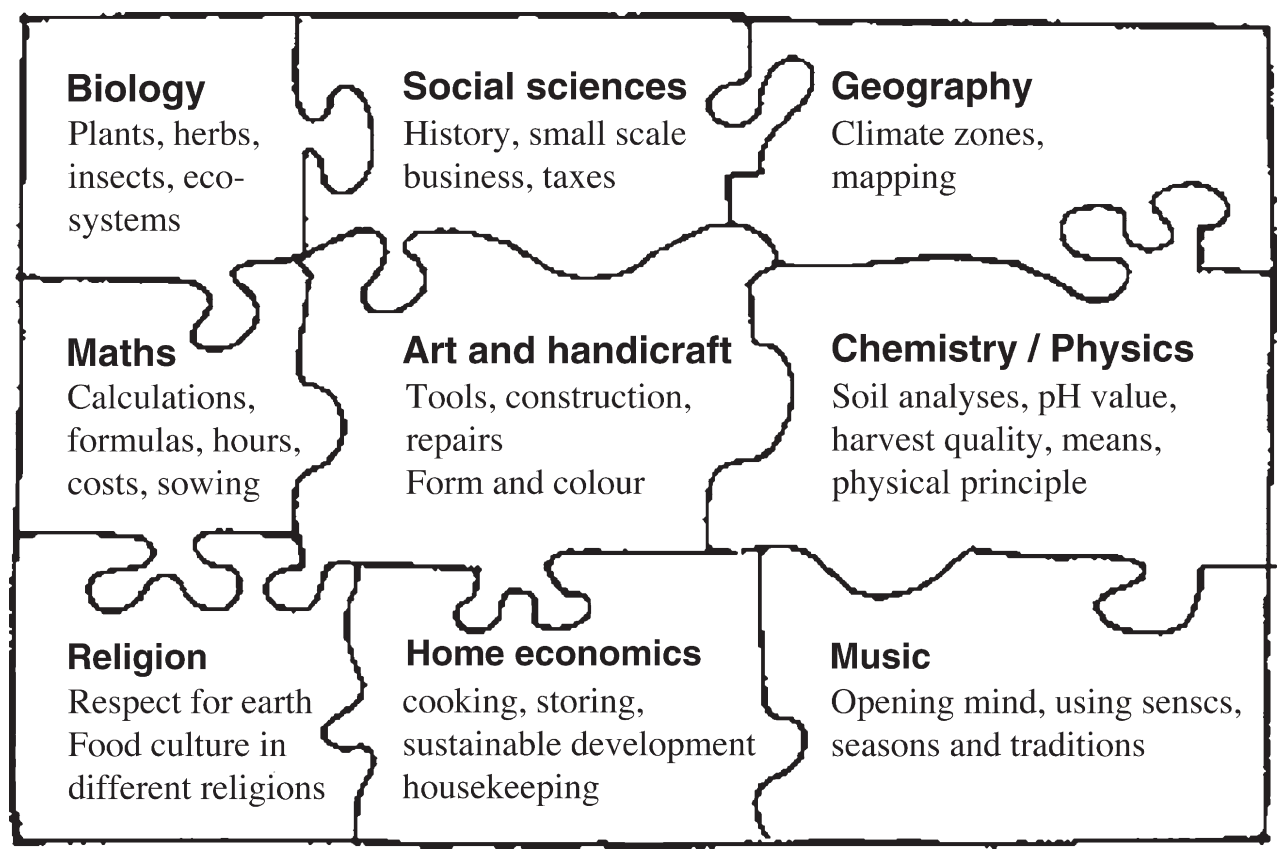

Fig. 4. "Puzzle" illustrating how school subjects can be used in an agricultural school project.

is an example of how the staff together can combine ordinary life and school work in a way that encourages both learning of school subjects and health-promoting skills. The same sort of subject-integrated thinking could be used for education about food, cooking, eating habits, physical activity and fitness. Art, music and handicraft, as well as maths, geography, social sciences, religion, chemistry and biology, can provide different aspects of healthy eating at different periods and in different societies. In all of the school subjects, divergent perspectives on health and food choice can be considered which can result in deeper understanding and new practice. As a starting point, a country, a historical epoch or work of art or music could be used. The idea, however, is to combine that starting point with social and life sciences to enhance students' comprehension of the human body and societal conditions to help them to understand the scientific basis for health promotion (30).

\section{Conclusions for health promotion in schools}

Health promotion and school development can be understood as methods of empowerment, participation and deliberative democracy. They can equally well be understood as ways of manipulation and disciplining children from low-income families. A democratic approach to health promotion means emphasizing the "opposite" question and empowerment, instead of education for the "right" answers. This is a challenge to the whole school sector. For an encounter to take place all the dialogical and deliberative competence that can be captured will be needed.

\section{References}

1. Nutbeam D, Smith C, Moore L, Bauman A. Warning! Schools can damage your health: alienation from school and its impact on health behaviour. J Paediatr Child Health 1993; 29(Suppl 1): 25-30.

2. Cummins J. Empowering minority students: a framework for intervention. Harv Educ Rev 1986; 56: 18-36.

3. Madsén $T$, Sandström I. Livlina för livslångt lärande (Lifeline for lifelong learning). Stockholm: Utbildningsdepartementet; 1989. (In Swedish.)

4. World Health Organization. The European Network of Health Promoting Schools. A joint WHO-CE-CEC Project. Copenhagen: WHO Regional Office for Europe; 1993.

5. World Health Organization. Comprehensive school health education and promotion. Geneva: WHO Press Office; 1995.

6. World Health Organization. Promoting health through schools: report of a WHO expert committee on comprehensive school health education and promotion. Geneva: WHO; 1997.

7. Ziglio E. Why is the education sector so important for the people working with health? Network news. 4th ed. 
European Network of Health Promoting Schools; 1998. p. 2.

8. St Leger L. The opportunities and effectiveness of the health promoting primary school in improving child health - a review of the claims and evidence. Health Educ Res 1999; 14: 51-69.

9. Olsson U. Folkhälsa som pedagogiskt projekt. Bilden av hälsoupplysning i statens offentliga utredningar (Public health as a pedagogical project). Uppsala Studies in Education 72. Acta Universitatis Upsaliensis; 1997. (Summary in English.)

10. Rutter M, Maughan B, Mortimore P, Ouston J. Fifteen thousand hours. Secondary schools and their effects on children. London: Open Books; 1979.

11. Berg G, Scherp H-Å, ed. Skolutvecklingens många ansikten (The many faces of school development). Stockholm: Myndigheten för skolutveckling/Liber; 2003. (Summary in English.) http://www.skolutveckling.se/publikationer/publ/main?uri $=$ scam $\% 3 \mathrm{~A} \% 2 \mathrm{~F} \% 2$ Fpubl $\% 2 F 137 \& \mathrm{cmd}=$ download

12. Antonovsky A. Health, stress and coping. San Francisco: Jossey-Bass; 1979.

13. Antonovsky A. Unraveling the mystery of health. San Francisco: Jossey-Bass; 1987.

14. Antonovsky A. The salutogenic model as a theory to guide health promotion. Health Promot Int 1996; 11: $11-8$.

15. International Union for Health Promotion and Education. Effective health promotion in schools. In: The evidence of health promotion. Part 2. Brussels: IUHPE; 1999. Chapter 10.

16. Devaney B, Schochet P, Thorton C, Fasciano N, Gavin A. Evaluating the effects of school health intervention on school performance: design report. Princeton, NJ: Mathematica Policy Research; 1993.

17. Symons C, Cinelli B, James T, Groff P. Bridging student health risks and academic achievement through comprehensive school health programs. J Sch Health 1997; 67: $220-7$.

18. Hawkins D, Catalano R. Broadening the vision of education: schools as health promoting environments. J Sch Health 1990; 60: 178-81.

19. Slavin R, Karweit N, Wasik B. Preventing early school failure: research, policy and practice. Boston, MA: Allyn and Bacon; 1994.

20. O’Donnell J, Hawkins D, Catalano R, Abbott R, Day E. Preventing school failure, drug use and delinquency among low-income children: long-term intervention in elementary schools. Am J Orthopsychiatry 1995; 65: 87100.

21. Whitty G, Aggleton P, Gamarnikow E, Tyrer P. Education and health inequalities. Input Paper 10 to the Independent Inquiry into Inequalities in Health, January 1998. J Educ Policy 1998; 13: 641-52.

22. Nutbeam D, Aarø LE. Smoking and pupil attitudes towards school: the implications for health education with young people. Results from the WHO study of health behaviour among schoolchildren. Health Educ Res Theory Pract 1991; 6: 415-21.

23. Franke-Wikberg S. Utvärderingens mångfald: Några ledtrådar för vilsna utbildare (The multiplicity of evaluation). Stockholm: FoU-enheten, UHÄ; 1992. (In Swedish.)

24. Schön D. The reflective practitioner. How professionals think in action. New York: Basic Books; 1983.

25. Nilsson L, Lindström B. Learning as a health promoting process. IJHP Articles. www.rhpeo.org/ijhp-articles/ 1998/14.

26. Kalnins I, McQueen D, Backett K, Curtice L, Currie C. Children, empowerment and health promotion: some new directions in research and practice. Health Promot Int 1992; 7: 53-9.

27. Rissel C. Empowerment: the holy grail of health promotion? Health Promot Int 1994; 9: 39-47.

28. Forsberg E, Starrin B. Frigörande kraft. Empowerment som modell i skola, omsorg och arbetsliv (Emancipation of power). Stockholm: Gothia; 1997. (In Swedish.)

29. Nilsson L. Hälsoarbetets möte med skolan i teori och praktik (The encounter between health promotion work and school). Örebro Studies in Education No. 7. Dissertation, Örebro University; 2003. (Summary in English.)

30. Kolbe L. An essential strategy to improve the health and education of Americans. Prev Med 1993; 22: 544-60.

Lena A Nilsson, FD

Department of Nursing, Health and Culture

University of Trollhattan-Uddevalla Box 1236

SE-462 28 Vänersborg

Sweden

E-mail: lena.a.nilsson@htu.se 